\title{
Incidence of submacular haemorrhage (SMH) in Scotland: a Scottish Ophthalmic Surveillance Unit (SOSU) study
}

\author{
Aws Al-Hity $\mathbb{D}^{1} \cdot$ David H. Steel $^{1} \cdot$ David Yorston $^{2} \cdot$ David Gilmour $^{1} \cdot$ Zachariah Koshy $^{3} \cdot$ David Young $^{4}$. \\ Jost Hillenkamp ${ }^{5}$. Gerard McGowan ${ }^{1}$
}

Received: 2 March 2018 / Revised: 2 August 2018 / Accepted: 7 August 2018 / Published online: 29 October 2018

(c) The Royal College of Ophthalmologists 2018

\begin{abstract}
Purpose Submacular haemorrhage (SMH) is a cause of severe visual loss in neovascular age-related macular degeneration (nAMD). The incidence is uncertain and furthermore there is no widely used classification system nor agreed best practice. The aim of this national surveillance study was to identify the incidence, presenting features and clinical course of new fovea-involving submacular haemorrhage associated with nAMD.

Methods A questionnaire was sent monthly to every ophthalmic specialist in Scotland over a 12-month period asking them to report all newly presenting patients with acute SMH secondary to nAMD of at least two disc diameters (DDs) in greatest linear diameter. A follow-up questionnaire was sent 6 months after initial presentation. Cases related to other causes were excluded.

Results Twenty-nine cases were reported giving an incidence of 5.4 per million per annum (range 2-15). The mean age was 83 years (range 66-96) and females accounted for 17/29 (59\%). Fifteen of the 29 cases (52\%) had a past history of AMD, of which 7 had nAMD. Nineteen of the 29 cases $(66 \%)$ presented within 7 days of onset and the majority had SMH of $<11$ DD $(20 / 29,69 \%)$. Treatment options comprised the following: observation $(n=6,21 \%)$, anti-VEGF alone $(n=6,21 \%)$ or vitrectomy with co-application of tissue plasminogen activator (TPA), anti-VEGF and gas $(n=17,58 \%)$. The vitrectomy group experienced the greatest change in vision from $\log$ MAR $1.89-1.50(p=0.374)$. Four of $20(20 \%)$ cases with 6 months follow-up suffered a re-bleed at a mean time of 96 days.

Conclusions The incidence, clinical features and course of a consecutive national cohort of patients with SMH secondary to nAMD are presented.
\end{abstract}

\section{Introduction}

The prognosis for neovascular age-related macular degeneration (nAMD) has been transformed by the use of intravitreal anti-vascular endothelial growth factor (anti-VEGF) drugs. Some patients, however, still have poor outcomes. One cause of severe visual loss in nAMD is submacular

Electronic supplementary material The online version of this article (https://doi.org/10.1038/s41433-018-0239-4) contains supplementary material, which is available to authorised users.

Aws Al-Hity

alhitya@gmail.com

1 Tennent Institute of Ophthalmology, Gartnavel General Hospital, 1053 Great Western Road, Glasgow G12 0YN, UK

2 Sunderland Eye Infirmary, Sunderland, Institute of Genetic haemorrhage (SMH). Although the incidence of SMH is illdefined, it is known to be relatively uncommon and has a very poor prognosis untreated [1].

The optimum treatment of wet AMD complicated by significant SMH is uncertain. To date, several studies have suggested that treatment with anti-VEGFs alone may be superior to observation, whereas others have suggested that displacement of blood with gas and subretinal or intravitreal tissue plasminogen activator (TPA) and anti-VEGF may be more optimal. Identifying the incidence of this complication and its optimal treatment has obvious implications for public health and cost effectiveness [2-8].

Medicine, Newcastle University, Newcastle, UK

3 University Hospital Ayr, Ayr, UK

4 Department of Mathematics and Statistics, University of Strathclyde, Glasgow, UK

5 Kiel University, Kiel, Germany 
The best evidence to determine whether these more invasive procedures really represent an advance over management with intravitreal anti-VEGF alone would be a randomised clinical trial. To assist the design of such a trial, data on the incidence, natural history and outcome of a consecutive series of non-selected patients presenting with $\mathrm{SMH}$ in the era of anti-VEGF treatment is needed. We therefore designed a prospective observational study in Scotland, UK. Specifically, we aimed to assess the incidence of SMH occurring secondary to nAMD, the clinical features at presentation, the treatment modalities currently being used and finally prognostic factors that could help in future decision-making.

\section{Methods}

This was a nationwide, prospective observational study with active surveillance of cases through the Scottish Ophthalmological Surveillance Unit (SOSU) monthly reporting card scheme. SOSU has the same methodology as its sister organisation, the British Ophthalmological Surveillance Unit (BOSU) where several studies have been conducted previously [9-13]. Both were established to assist in the investigation of the incidence and clinical features of rare eye conditions of scientific and public health importance. The BOSU steering committee review all protocols of individual studies in order that certain basic criteria are met and to provide advice on the design of their questionnaires and studies [14].

The SOSU surveillance scheme involves all consultant or associate specialist ophthalmologists with clinical autonomy in Scotland, who form the reporting base. Ophthalmologists were asked to notify the study investigators, through the SOSU of all newly diagnosed cases of fovea-involving SMH of size $>2$ DD. Case notifications were requested over the 12-month study period September 2013 to September 2014. All SMH not related to AMD were excluded.

Following case notification to the SOSU, every consultant ophthalmologist in Scotland was sent a detailed questionnaire by the study investigators requesting data on the following: visual acuity, lens status, fellow eye status, duration of symptoms (recorded as 1-7, 8-14 and > 14 days), previous treatment for $\mathrm{SMH}$, size of haemorrhage (recorded in groups 2-6, 7-11, 12-16 and > 16 disc diameters (DDs)), past history of nAMD, ocular co-morbidities, time to treatment and initial management. Snellen visual acuity was converted to $\log$ MAR equivalent ( $6 / 6$ being 0.00 , $6 / 60$ being 1.00). Vision worse that $6 / 60$ (counting fingers and hand motions was ascertained using the Freiburg Visual Acuity Test and determined to be 2.0 and 2.3 respectively) [15]. Outcome data were obtained from follow-up questionnaires sent to the reporting ophthalmologists 6 months after diagnosis (questionnaires available as Supplementary Material). Follow-up data collected comprised the following: subsequent treatment (within the 6-month follow-up period), follow-up visual acuity and complications (re-bleed). Those who did not return questionnaires were sent repeat request letters at 2 and 3 months after the initial request had been sent. The response rate was calculated as the number of questionnaires received over the total reporting cards received [14].

Statistical analysis was performed with presentation of mean or median and range as appropriate. Visual acuity was converted to $\log$ MAR for analysis and non-parametric multi-group tests (Wilcoxon) used to compare vision pre and post intervention. Non-parametric multi-group analysis was also performed to identify whether various risk factors (size of haemorrhage, duration of symptoms and nature of intervention) have an impact on visual acuity at 6-month follow-up. A $p$-value of $<0.05$ was considered significant.

\section{Incidence rate}

Scotland has been recognised in previous studies as a welldefined region with stable population demographics [11, 16]. The proportion of the Scottish population of retirement age (65 years) has been shown to be relatively stable and representative of the whole UK population (18.0\% vs. $17.7 \%$, respectively) and as such the Scottish population can be used as a focus population in a similar manner to previous studies [11, 16]. The male to female ratio is $17: 12$. The incidence was calculated as the number of reported cases as a proportion of the total population over the 1-year study period the number of cases were also tracked to the source National Health Service (NHS) trust, in order to calculate the incidence for each of the eight Scottish regions.

\section{Results}

Over the 12-month period between September 2013 and September 2014, a total of 29 reported cases and 29 initial questionnaires received giving a response rate of $100 \%$. Six-month follow-up data were received on 20 of the 29 cases. The total Scottish population in 2013 was 5,327,700, giving an overall incidence of 5.4 per million per annum [17]. The incidence varied by region from 15 per million per annum in the Greater Glasgow and Clyde region (17 cases with a population of $1,137,000)$ to 2 per million per annum in the Grampian region (1 case with a population of 526,000) (Table 1) [18].

The baseline data are presented in Table 2. The mean age was 83 years with 17 (59\%) females. Fifteen (52\%) had a past history of AMD of which 7 were nAMD. A total of 19/ $29(66 \%)$ presented within 1-7 days of onset of symptoms. 
Table 1 Reported cases and incidence per regional Scottish NHS trusts [17]

\begin{tabular}{llll}
\hline Trust of reported cases & $\begin{array}{l}\text { Population } \\
\text { estimate }\end{array}$ & Cases & Incidence \\
\hline $\begin{array}{l}\text { NHS Greater Glasgow and } \\
\text { Clyde }\end{array}$ & $1,137,000$ & 17 & 15.0 \\
NHS Ayrshire and Arran & 400,000 & 3 & 7.5 \\
NHS Tayside & 415,000 & 2 & 4.8 \\
NHS Lothian & 800,000 & 3 & 3.8 \\
NHS Forth Valley & 281,000 & 1 & 3.6 \\
NHS Highland & 320,000 & 1 & 3.1 \\
NHS Fife & 359,000 & 1 & 2.8 \\
NHS Grampian & 526,000 & 1 & 1.9 \\
\hline
\end{tabular}

Seven of the 29 cases $(24 \%)$ presented $>2$ weeks after onset of symptoms. Eleven (38\%) had a SMH of size 7-11 DD, whereas a further $9 / 29(31 \%)$ were of size 2-6 DD.

\section{Treatment modalities}

There were three management strategies observed: observation, anti-VEGF agents alone (either ranibizumab or aflibercept), and vitrectomy and co-application of intravitreal or subretinal tPA/anti-VEGF (see Table 2). No cases with expansile gas and intravitreal tPA/anti-VEGF were reported either as initial treatment or subsequently.

\section{Visual acuity}

Overall, the mean visual acuity non-significantly improved from 1.85 at baseline to $1.61(p=0.072)$ with differences, again nonsignificant between the groups, but with the greatest effect seen in the vitrectomy group (1.89 to $1.50, p=0.374)$. The eligibility for treatment in the UK NHS is dependent on being better than the UK National Institute of Clinical Excellence visual acuity cutoff of 25 ETDRS (Early treatment of diabetic retinopathy study) letters (1.20 logMAR) or better. Of the 29 cases, 6 (20.7\%) met these criteria at baseline. This percentage rose to $35.0 \%(7 / 20)$ at follow-up. Subsequent treatment was given in 13/20 (65.0\%) of cases, all receiving intravitreal ranibizumab. The mean number of injections given was 2 (range 1-6) (Table 3).

\section{Duration of symptoms}

Those presenting within the median of 1-7 days of onset of symptoms showed a mean improvement in visual acuity from 1.76 to $1.37(p=0.27)$. However, the duration of symptoms was not a significant predictor of visual acuity at 6-month follow-up $(p=0.381)$.
Table 2 Clinical features at baseline

\begin{tabular}{|c|c|}
\hline Age, years (mean, range) & $83,66-96$ \\
\hline \multicolumn{2}{|l|}{$\operatorname{Sex} n(\%)$} \\
\hline Female & $17(59 \%)$ \\
\hline Male & $12(41 \%)$ \\
\hline Visual acuity, logMAR (mean, range) & $1.85,0.8-2.3$ \\
\hline Fellow eye visual acuity & $0.94,0.2-2.3$ \\
\hline \multicolumn{2}{|l|}{ Duration of symptoms, days $n(\%)$} \\
\hline $1-7$ & $19(66 \%)$ \\
\hline $8-13>14$ & $3(10 \%) 7(24 \%)$ \\
\hline \multicolumn{2}{|l|}{ Size of SMH, DD $n(\%)$} \\
\hline $2-6$ & $9(31 \%)$ \\
\hline $7-11$ & $11(38 \%)$ \\
\hline $12-16$ & $3(10 \%)$ \\
\hline$>16$ & $6(21 \%)$ \\
\hline \multicolumn{2}{|c|}{ Known ocular co-morbidity of affected eye $n(\%)$} \\
\hline None & $13(45 \%)$ \\
\hline Dry AMD & $8(28 \%)$ \\
\hline nAMD & $7(24 \%)$ \\
\hline OHT & $1(3 \%)$ \\
\hline \multicolumn{2}{|l|}{ Lens status $n(\%)$} \\
\hline Phakic & $20(69 \%)$ \\
\hline Pseudophakic & $9(31 \%)$ \\
\hline \multicolumn{2}{|l|}{ Initial treatment $n(\%)$} \\
\hline Observation & $6(21 \%)$ \\
\hline IVT aflibercept & $1(3 \%)$ \\
\hline IVT ranibizumab & $5(17 \%)$ \\
\hline PPV/ SRET tPA and ranibizumab/gas & $17(58 \%)$ \\
\hline \multicolumn{2}{|l|}{ Time to treatment (days) mean (range) } \\
\hline Anti-VEGF & $38(6-55)$ \\
\hline Vitrectomy & $3(0-6)$ \\
\hline Overall & $10(0-55)$ \\
\hline
\end{tabular}

$A M D$ age-related macular degeneration, $D D$ disc diameter, IVT intravitreal, $n A M D$ neovascular age-related macular degeneration, $S M H$ submacular haemorrhage, SRET subretinal, $P P V$ pars plana vitrectomy, $V A$ visual acuity. $N=29$ for all values

\section{Size of haemorrhage}

The median size of SMH was 7-11 DD. There were no significant differences in baseline and follow-up between any of the groups but the greatest improvement was seen in the smallest SMH size group of 2-6 DD $(p=1.00)$ In contrast, a decline in mean visual acuity was seen in haemorrhages of $>16$ DD (see Table 4).

\section{Complications}

A total of 4/20 (20\%) suffered re-bleeds with a mean time of 96 days (range 52-170) from the date of treatment. One case was in the observation group, whereas the other three 
were in the surgical group. The mean visual acuity in this group improved from 1.95 to 1.77 despite the re-bleed. Three out the four $(75 \%)$ were treated with subsequent antiVEGF.

\section{Discussion}

In this study, we present data from a national surveillance study into all cases of acute SMH over a 12-month period in Scotland. Through this prospective study, we have identified an incidence rate of fovea-involving SMH of 5.4 per million per annum. It was noted on postcode data that the incidence varied greatly by region ranging from 15 per million to 2 per million per annum. There are a number of reasons for these variations. The first may be a degree of under-reporting, which is evident in any surveillance scheme, although the response rate from participating ophthalmologists in the BOSU scheme has been consistently more than $70 \%$ [14]. Second, patients may fail to present due to access to healthcare. For example, NHS Highland covers an estimated area of 12,500 square miles and serves a population of 320,000 [18]. In contrast to this, NHS Greater Glasgow and Clyde has a population of $1,137,000$ and 17 reported cases (incident rate of 15 per million per annum). With an area of 452 square miles, the population density of Glasgow and Clyde is much higher

Table 3 Follow-up data

Subsequent treatment (anytime within the 6-month follow-up period) $n$ (\%)

\begin{tabular}{ll}
\hline None & $7(35 \%)$ \\
IVT ranibizumab & $13(65 \%)$ \\
6-Month visual acuity (mean, range) & $1.61,0-2.3$ \\
6-Month visual acuity fellow eye (mean, range) & $0.91,0-2.3$ \\
Re-bleed $n(\%)$ & $4(20 \%)$ \\
Sight impairment registration $n(\%)$ & \\
$\quad$ None & $10(50 \%)$ \\
Sight impairment & $5(25 \%)$ \\
Severe sight impairment & $3(15)$ \\
Not known & $2(10 \%)$ \\
\hline
\end{tabular}

IVT intravitreal, VA visual acuity. $N=20$ for all values than NHS Highland at 2515 people per square mile, compared with just 26 people per square mile [18]. This might have contributed to the variations in reporting rates. One can also suppose that these differences across regions are genuine; however, this was not seen in a pilot study, which showed comparable incidence rates between Sunderland and Glasgow (24 per million per annum), although these are very comparable areas in terms of population density, healthcare provision and deprivation indices [8].

In our study, those that were observed showed a slight decline in visual acuity, whereas those who were treated surgically showed a nonsignificant improvement in visual acuity. Patients treated with anti-VEGF agents alone resulted in maintained and in certain cases, improved visual outcomes compared to the natural history of the SMH, which concurs with previous reports [2, 4, 19-23].

There appears to be a delay in treatment time when patient is managed non-surgically as compared with managing surgically. This may reflect the improvement in visual acuity when looking at the surgical group vs. nonsurgical group. This limitation of the study means that robust comparisons between surgical and non-surgical groups cannot be inferred. The pressures of service delivery, especially in the National Health service, mean that it is often days or weeks until patients are seen, have the appropriate diagnostic investigations, a management plan is arranged and executed. Strategies to highlight time-sensitive conditions such as SMH must be in place if severe visual loss is to be prevented. There were no reported cases of the use of pneumatic displacement with intravitreal tPA, although this has been widely reported as an effective strategy combined with anti-VEGFs previously [19-21, 24, 25]. Having said this, the relative efficacy of expansile gas and intravitreal TPA compared with vitrectomy with subretinal TPA and air or gas is uncertain. A recent randomised controlled trial showed no difference in results between the two modalities but previous studies have shown a higher efficacy of subretinal TPA over intravitreal TPA in terms of displacement of blood eccentrically to fovea [26, 27]. A study of vitrectomy combined with subretinal TPA and air reported three cases that were successfully displaced that had previously failed to displace with expansile gas and intravitreal TPA, and the vitrectomy technique may offer
Table 4 Changes in visual acuity with different size of submacular haemorrhage

\begin{tabular}{|c|c|c|c|c|c|c|c|c|c|}
\hline \multirow[t]{2}{*}{ Size of SMH (DD) } & \multirow[t]{2}{*}{$n$} & \multicolumn{3}{|c|}{ Baseline VA } & \multicolumn{3}{|c|}{ Final VA } & \multirow[t]{2}{*}{ Change in VA } & \multirow[t]{2}{*}{$p$-value } \\
\hline & & VA & SD & Range & VA & SD & Range & & \\
\hline $2-6$ & 9 & 1.51 & 0.48 & $1.04-2.00$ & 1.21 & 0.26 & $1.14-1.5$ & -0.3 & 1.00 \\
\hline $7-11$ & 11 & 1.8 & 0.6 & $0.8-2.30$ & 1.73 & 0.89 & $0.50-3.00$ & -0.07 & 0.855 \\
\hline $12-16$ & 3 & 2.2 & 0.17 & $2.00-2.30$ & 2.15 & 0.21 & $2.00-2.30$ & -0.05 & 1.00 \\
\hline$>16$ & 6 & 1.74 & 0.6 & $1.00-2.30$ & 1.78 & 0.56 & $0.8-2.30$ & 0.04 & 0.787 \\
\hline
\end{tabular}

$D D$ disc diameter, $V A$ visual acuity 
advantages in patients unable to posture [5]. It appears that in Scotland displacement with the expansile is not popular, which may be due to a variety of possible reasons including personal surgical preference, patient choice and the lack of ability, or perceived risks of posturing in the age group affected [25].

The evidence base for the treatment of SMH associated with AMD largely comprises case series, which tend to focus on surgeon-selected cases and a variety of criteria to guide individual treatment choices. Therapeutic decisionmaking is difficult due to a lack of standardisation in both the classification of SMH and outcome reporting [28]. The strength of this study is that we report on the presentation and management of all cases over a 1-year period with 6month follow-up data to give a true picture of the cases seen in clinical practice and real-world outcomes from a range of management options and which we hope will help guide the design of a future randomised controlled trial. There are however several limitations to the study, including the lack of access to fundal imaging to ascertain the precise features of the haemorrhages and absence of protocol refracted visual acuities. Follow-up was also limited to 6 months and incomplete.

In conclusion, this prospective national surveillance study has identified an incidence for SMH of 5.4 per million per annum but with a wide range of $2-15$. It is hoped that this surveillance study will inform future randomised control studies. In particular, further studies are indicated to clearly define the role of surgical intervention as compared with anti-VEGF treatment alone in the treatment of foveainvolving SMH.

\section{Summary}

\section{What was known before}

- Submacular haemorrhage is a condition managed in a variety of ways with no agreed best practice and no incidence.

\section{What this study adds}

- Establishment of an incidence rate, variations in practice and impact of various risk factors on visual outcome.

\footnotetext{
Acknowledgements We are very grateful for the opportunity to perform this project in conjunction with the Scottish Ophthalmic Surveillance Unit and wish to thank Mr Barny Foot for his valuable advice. We also acknowledge the contribution of the ophthalmologists throughout Scotland, who made this study possible by reporting cases to the SOSU and providing the necessary information about the patients.
}

\section{Compliance with ethical standards}

Conflict of interest The authors declare that they have no conflict of interest.

\section{References}

1. Scupola A, Coscas G, Soubrane G, Balestrazzi E. Natural history of macular subretinal hemorrhage in age-related macular degeneration. Ophthalmologica. 1999;213:97-102.

2. Stifter E, Michels S, Prager F, Georgopoulos M, Polak K, Hirn C, et al. Intravitreal bevacizumab therapy for neovascular age-related macular degeneration with large submacular hemorrhage. Am J Ophthalmol. 2007;144:886-92.

3. Bressler NM, Bressler SB, Childs AL, Haller JA, Hawkins BS, Lewis H, et al. Surgery for hemorrhagic choroidal neovascular lesions of age-related macular degeneration: ophthalmic findings: SST report no. 13. Ophthalmology. 2004;111:1993-2006.

4. Chang MA, Do DV, Bressler SB, Cassard SD, Gower EW, Bressler NM. Prospective one-year study of ranibizumab for predominantly hemorrhagic choroidal neovascular lesions in agerelated macular degeneration. Retina. 2010;30:1171-6.

5. Sandhu SS, Manvikar S, Steel DHW. Displacement of submacular hemorrhage associated with age-related macular degeneration using vitrectomy and submacular tPA injection followed by intravitreal ranibizumab. Clin Ophthalmol. 2010;4:637-42.

6. Treumer F, Roider J, Hillenkamp J. Long-term outcome of subretinal coapplication of rtPA and bevacizumab followed by repeated intravitreal anti-VEGF injections for neovascular AMD with submacular haemorrhage. Br J Ophthalmol. 2012;96:708-13.

7. Gonzalez-Lopez JJ. Vitrectomy with subretinal tissue plasminogen activator and ranibizumab for submacular haemorrhages secondary to age-related macular degeneration: retrospective case series of 45 consecutive cases. Eye (R Coll Ophthalmol). 2016;30:929-35.

8. McGowan G, Steel DHW, Yorston D. AMD with submacular hemorrhage: new insights from a population-based study. Invest Ophthalmol Vis Sci. 2014;55:662.

9. Agrawal A, McKibbin M. Purtscher's retinopathy: epidemiology, clinical features and outcome. Br J Ophthalmol. 2007;91:1456-9.

10. Kamalarajah S, Silvestri G, Sharma N, Khan A, Foot B, Ling R, et al. Surveillance of endophthalmitis following cataract surgery in the UK. Eye. 2004;18:580-7.

11. Desai P, MacEwen CJ, Baines P, Minassian DC. Incidence of cases of ocular trauma admitted to hospital and incidence of blinding outcome. Br J Ophthalmol. 1996;80:592-6.

12. Murphy C, Livingstone I, Foot B, Murgatroyd H, MacEwen CJ. Orbital cellulitis in Scotland: current incidence, aetiology, management and outcomes. Br J Ophthalmol. 2014;98:1575-8.

13. Lyall DAM, Tey A, Foot B, Roxburgh STD, Virdi M, Robertson $\mathrm{C}$, et al. Post-intravitreal anti-VEGF endophthalmitis in the United Kingdom: incidence, features, risk factors, and outcomes. Eye. 2012;26:1517-26.

14. Foot B, Stanford M, Rahi J, Thompson J, British Ophthalmological Surveillance Unit Steering Committee. The British Ophthalmological Surveillance Unit: an evaluation of the first 3 years. Eye. 2003;17:9-15.

15. Schulze-Bonsel K, Feltgen N, Burau H, Hansen L, Bach M. Visual acuities "hand motion" and "counting fingers" can be quantified with the freiburg visual acuity test. Invest Ophthalmol Vis Sci. 2006;47:1236-40.

16. Mitry D, Charteris DG, Yorston D, Siddiqui MAR, Campbell H, Murphy A, et al. The epidemiology and socioeconomic associations of retinal detachment in Scotland: a two-year prospective populationbased study. Invest Ophthalmol Vis Sci. 2010;51:4963-8. 
17. Office of National Statistics. Key population and vital statistics. 2014; Available at: https://www.ons.gov.uk/peoplepopulationandcommunity/populationandmigration/populationestimates/bulletins/annualmidyearpopulationestimates/2015-06-25. Accessed September 2014.

18. Scotland's Health on the Web. Scotland's Health on the Web. 2017; Available at: http://www.scot.nhs.uk/organisations/. Accessed 03 February 2017.

19. Stanescu-Segall D, Balta F, Jackson TL. Submacular hemorrhage in neovascular age-related macular degeneration: a synthesis of the literature. Surv Ophthalmol. 2016;61:18-32.

20. McKibbin M, Papastefanou V, Matthews B, Cook H, Downey L. Ranibizumab monotherapy for sub-foveal haemorrhage secondary to choroidal neovascularisation in age-related macular degeneration. Eye. 2010;24:994-8.

21. Shienbaum G, Garcia Filho CAA, Flynn HWJ, Nunes RP, Smiddy WE, Rosenfeld PJ. Management of submacular hemorrhage secondary to neovascular age-related macular degeneration with antivascular endothelial growth factor monotherapy. Am J Ophthalmol. 2013;155:1009-13.

22. Iacono P, Parodi MB, Introini U, La Spina C, Varano M, Bandello F. Intravitreal ranibizumab for choroidal neovascularization with large submacular hemorrhage in age-related macular degeneration. Retina. 2014;34:281-7.
23. Kim JH, Chang YS, Kim JW, Kim CG, Yoo SJ, Cho HJ. Intravitreal anti-vascular endothelial growth factor for submacular hemorrhage from choroidal neovascularization. Ophthalmology. 2014;121:926-35.

24. Papavasileiou E, Steel DHW, Liazos E, McHugh D, Jackson TL. Intravitreal tissue plasminogen activator, perfluoropropane (C3F8), and ranibizumab or photodynamic therapy for submacular hemorrhage secondary to wet age-related macular degeneration. Retina. 2013;33:846-53.

25. Steel DHW, Sandhu SS. Submacular haemorrhages associated with neovascular age-related macular degeneration. $\mathrm{Br} \mathrm{J}$ Ophthalmol. 2011;95:1051-7.

26. de Jong JH, van Zeeburg EJT, Cereda MG, van Velthoven MEJ, Faridpooya K, Vermeer KA, et al. Intravitreal versus subretinal administration of recombinant tissue plasminogen activator combined with gas for acute submacular hemorrhages due to agerelated macular degeneration: an Exploratory Prospective Study. Retina. 2016;36:914-25.

27. Hillenkamp J, Surguch V, Framme C, Gabel V, Sachs HG. Management of submacular hemorrhage with intravitreal versus subretinal injection of recombinant tissue plasminogen activator. Graefes Arch Clin Exp Ophthalmol. 2010;248:5-11.

28. Bopp S. [Subretinal hemorrhage. Natural course and staging]. Ophthalmologe. 2012;109:635-43. 